\title{
Development of Transparent and Flexible Thin Film from Hybrid Alloy using Deposition by Evaporation Technique
}

\author{
Abdellah Mrij*, Abdelmajid El Bakkali, Jaouad Foshi \\ Team Electronics, Instrumentation and Measurement, Department of Physics, Faculty of Sciences and Techniques, University Moulay Ismail, BP 509, \\ Boutalamine, Errachidia, Morocco.
}

\section{A R T I C L E D E T A I L S}

\section{Article history:}

Received 28 August 2019

Accepted 06 September 2019

Available online 23 September 2019

\section{Keywords:}

Chemical Deposition

Thin Film

Electric Impedance

Optical Reflection Coefficient

\begin{abstract}
A B S T R A C T
This work presents the fabrication process of an intelligent thin film from a hybrid compound to realize transparency and flexibility characteristics. Various delicate operations are encountered during preparation of the film such as exposition to radiations and baking in vacuum oven for many times. The built film with specifics materials improves the performances. The phase quality depends on the type of additives materials during preparation. The band gap of the film is controlled to permit reliability of the fabricated film and endurement of temperature variations. The fabricated thin film can be an alternative and crucial solution for many smart devices that are influenced by blazing and glazing limits. This work also parallelly represent the characteristics such as electrical impedance in function of temperature and optical reflection coefficient.
\end{abstract}

\section{Introduction}

The nanotechnology provides many routes includes transistor thin-film fabrication. It constitutes the core of smart device especially in electronic memory and liquid crystal display manufacturing. Also, this technology is widely used in many fields such as photovoltaic and advanced electronic devices, etc., [1]. In this work we studied a hybrid compound where many elements are implemented precisely $(\mathrm{Al}, \mathrm{Pb}, \mathrm{ZnO})$. The alloy has native tendency to n-type conductivity and suitable thermal conductivity. Moreover, the chemical kinds are easy to prepare and available. The materials that are used here are limited due to problems of glazing and blazing and there are hard steps during preparation. The process of semiconductor is based on either insulant or conductor and changing the content using impurities to adjust band gap which is relied to charge carrier density [2]. We noticed from literature that the materials properties and their compositions have influence on performances of alloys so that the choice of materials is delicate [3]. Different methods are adopted to film manufacturing processes either physical or chemical ones such as, deposition techniques, laser deposition, sputtering evaporation, chemically based nonvacuum deposition techniques and electrochemical deposition [4].

Our work is based on chemical evaporation and the goal is to ensure high quality of the film that has strong challenge with actuals films with the transparency and flexibility characteristics. In addition to that the materials $(\mathrm{Al}, \mathrm{Pb}, \mathrm{ZnO})$ are scaled to reduced potential range, electrical impedance and stable under oven phases changes like some thin films with reference to the literature [5]. Many researches are taking place in nanotechnologies, but the problems go with solid phase like smashing and bad quality due to restriction of optical and chemical properties [6-8]. Therefore, we are giving here an alternative method by changing the optical and morphological intrinsic properties of the compound [9]. We fabricated samples of thin film with appropriate performances especially flexibility, transparency and induration of thermal variations. The potential of a single element is hard to ensure suitable semiconductor. We used a hybrid alloy ( $\mathrm{Al}, \mathrm{Pb}, \mathrm{ZnO})$ to resolve this restriction. Therefore, we kept adequate potential gap and make easy the process of deposition by boosting the technique using catalysts such as acid medium and high temperature oven. Moreover, a good correspondence remarked between the $\mathrm{Pb}$ and $\mathrm{ZnO}$ that leads for others complexations [10]. The studied sample is rich in $\mathrm{Al}$ and poor on both $\mathrm{ZnO}$ and $\mathrm{Pb}$. The chemical composition depends on the abundance of each elements in the fabricated film. Yet, the quality of thin film is relied to the composition, so the experiment is based on many samples to make comparisons as inspired from example with different composition ratios $[11,12]$.

The developed thin film may be a novel one for nanotechnology. The improvement of optical and morphological characteristics is obtained subsequently in the experimental results. The film is qualified as a privileged one with its smallest size around few nanometers. Moreover, it has wonderful optical qualities. The solubility of these materials in diluted acid leads towards narrow superposition of layers with high performances. It ensures a suitable mobility and conductivity by doping diffusion to generate electron-holes $[13,14]$ that are necessary to the conduction of junctions. However, we noted that during the steps of thin film fabrication there are many holdbacks due phenomena of crystallization and oxidation. Therefore, the chemical composition and temperature of baking were adjusted upto the results obtained satisfactory. In fact, the goal is to keep high performances obtained directly after preparation and doping whatever the variations of ambient conditions more specifically the temperature variations. If the lead $(\mathrm{Pb})$ is included in $\mathrm{Si}, \mathrm{Ge}, \mathrm{Sn}$ and $\mathrm{C}$ family group, it can provide various uses. Therefore, the semiconductors based on these elements are characterized by low potential and adequate band gap. So, this element used as its derivative $\mathrm{PbCl}_{2}$ but with weak ratio to minimize toxic effect.

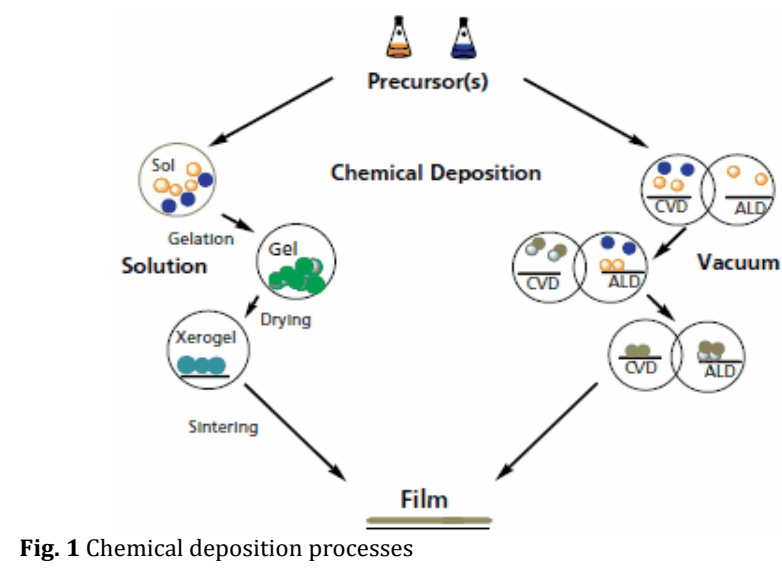


$\mathrm{ZnO}$ is a smart material that is often implemented in latest technologies. It is an inorganic compound, insoluble in water, and it has used as a large additive in numerous materials and products including rubbers, plastics, ceramics, glass and lubricants [15]. For example, it used in adhesives, sealants, foods, batteries and ferrites. Although, it is abundant naturally as the form of mineral zincite but most of the zinc oxides are produced synthetically [16]. ZnO has a wide-bandgap semiconductor of the II-VI semiconductor group. By adding impurities of aluminium and the privilege of native doping the semiconductor has tendency into n-type due to oxygen vacancies or zinc interstitials [17]. This work used it to get transparency, high electron mobility and wide band gap, those properties are valuable in emerging applications such as transparent electrodes in liquid crystal displays, and electronics as thin-film transistors and light emitting diodes. The chemical deposition processes are depicted by Fig. 1.

\section{Experimental Methods}

The goal of this work is to boost performances of existing thin films by getting transparency and flexibility properties with the manufacturing scale. The core idea is based on changing the phase such as the built of some alloys referred to the literature [18,19]. The composition of aluminium (Al) is rich when compared to the $\mathrm{PbCl}_{2}$ and $\mathrm{ZnO}$ to obtain the suitable electric impedance. The thin layer of aluminium was put under exposition of UV for $40 \mathrm{~min}$. After that the compound was placed on a substrate of polymers such as polycarbonate to endure drying process inside an oven for $20 \mathrm{~min}$ with temperature at $280{ }^{\circ} \mathrm{C}$. After that a transparent and flexible thin film was obtained. The impedance was calculated for various temperatures to confirm the accepted performances of this alloy film as done in previous work $[20,21]$. The deposited thin film was rinsed with distilled water and dried in the air. Then, the thin film was ready to be characterized by many techniques such as the reflection to laser beam. The testing voltage $0.8 \mathrm{~V}$ applied between two different sides of the film to verify conduction junction. To confirm the elements composition in the specimen thin film, emission of laser beam generated from DVD were readed and worked by $3 \mathrm{~V}$ as feed voltage. Then, the reflected voltage difference reveals the chemical composition. The laser beam was characterized by high frequency that reaches $140 \mathrm{TGHz}$ and wavelength at $650 \mathrm{~nm}$. Many important thin film parameters are characterized by the following Eqs.(1-4).

$$
\begin{aligned}
& \mathrm{P}=\mathrm{P}_{0} \cdot \exp \left(-\mathrm{E}_{\mathrm{a}} / \mathrm{RT}\right) \\
& \mathrm{R}=\rho \cdot \mathrm{L} / \mathrm{S} \\
& \mathrm{D}=\mathrm{P} / \mathrm{S} \\
& \mathrm{v}=\rho \cdot \mathrm{g} \cdot \mathrm{H}^{2} / \mu
\end{aligned}
$$

where P: Permeability $\left(\mathrm{m}^{2} / \mathrm{s}\right) ; \mathrm{P}_{0}$ : Constant of permeability $\left(\mathrm{m}^{2} / \mathrm{s}\right)$; $E_{a}$ : Activation energy $(\mathrm{eV}) ; \mathrm{T}$ : Temperature $(\mathrm{K})$; D: Diffusivity $\left(\mathrm{m}^{2} / \mathrm{s}\right)$; S: Solubility (g/L); $\rho$ : Density; g: Gravity $\left(\mathrm{m} / \mathrm{s}^{2}\right) ; \mu$ : Dynamic viscosity $\left(\mathrm{Kgm}^{2} / \mathrm{s}\right)$; H: Thickness of the film (nm) and v: Velocity (m/s).
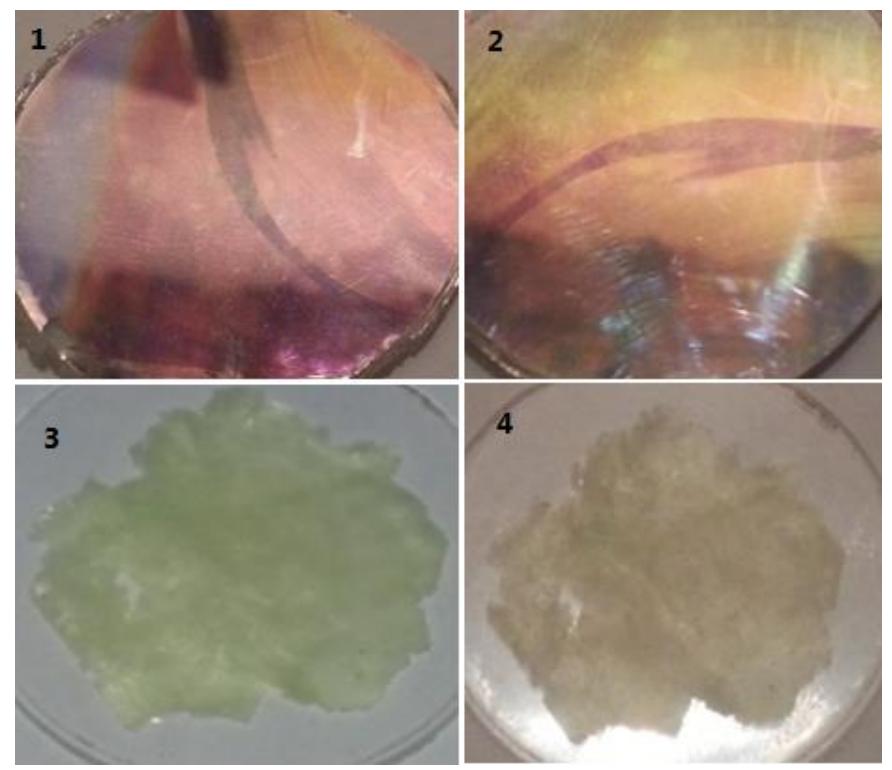

Fig. 2 Progression of results during preparation

The films can be characterized by many properties but this work used to study the reflection to laser beam exposition as an optical property. https://doi.org/10.30799/jtfr.021.19030103
Also, the electrical impedance measured that depends on chemical composition. The illustrative photos of the progressive experimental results as wafer are shown in the Fig. 2. The first step is a wafer of aluminium thin layer deposited on reliable substrate. However, the second one is the wafer after exposition to UV. Then, the mixture of lead and zinc is implemented. The final operation is drying inside oven for a specific duration.

\section{Results and Discussion}

Four specimens A, B, C and D were fabricated. Each one has its specific chemical composition of an alloy that contains three elements $(\mathrm{Al}, \mathrm{PbCl} 2$, $\mathrm{ZnO}$ ) as illustrated in Table 1.

Table 1 Chemical composition rates of prepared samples

\begin{tabular}{clll}
\hline Composition & $\mathrm{Al}($ at.\%) & $\mathrm{Pb}$ (at.\%) & $\mathrm{ZnO} \mathrm{(at. \% )}$ \\
\hline $\mathrm{A}$ & 62 & 24 & 14 \\
$\mathrm{~B}$ & 52 & 38 & 10 \\
$\mathrm{C}$ & 48 & 16 & 36 \\
$\mathrm{D}$ & 50 & 25 & 25 \\
\hline
\end{tabular}

Table 2 Chemical composition ratios of fabricated samples

\begin{tabular}{lll}
\hline Composition Ratio (\%) & $\mathrm{Pb} / \mathrm{Al}$ & $\mathrm{ZnO} / \mathrm{Al}$ \\
\hline $\mathrm{A}$ & 0.39 & 0.23 \\
$\mathrm{~B}$ & 0.73 & 0.19 \\
$\mathrm{C}$ & 0.33 & 0.75 \\
$\mathrm{D}$ & 0.50 & 0.50 \\
\hline
\end{tabular}

From the table, the effects of composition on electrical performances, optical and morphological properties were compared. It has noted that aluminium is in rich therein all specimens but with high ratio in $\mathrm{A}$. While the lead is used in second order for B specimen. For the third C specimen, $\mathrm{ZnO}$ is classified as the second one in abundance. However, in the fourth specimen $\mathrm{D}$, the $\mathrm{Pb}$ and $\mathrm{ZnO}$ are equals in the composition. The band gap is varying with chemical composition and disturbing factors such as oxidation and crystallization of molecules in nanoscale. We sum up the chemical composition of samples in Table 1.

Also, the distribution of chemical composition ratios for developed samples are listed in Table 2. The samples look different appearance due to their composition ratios. They have intrinsic properties that make them as suitable films. Also, they are characterized by accepted mobility and suitable diffusion to generate enough electrons-holes carriers that are required to conduction phenomenon at ambient conditions. The synthesised thin films are shown in Fig. 3.
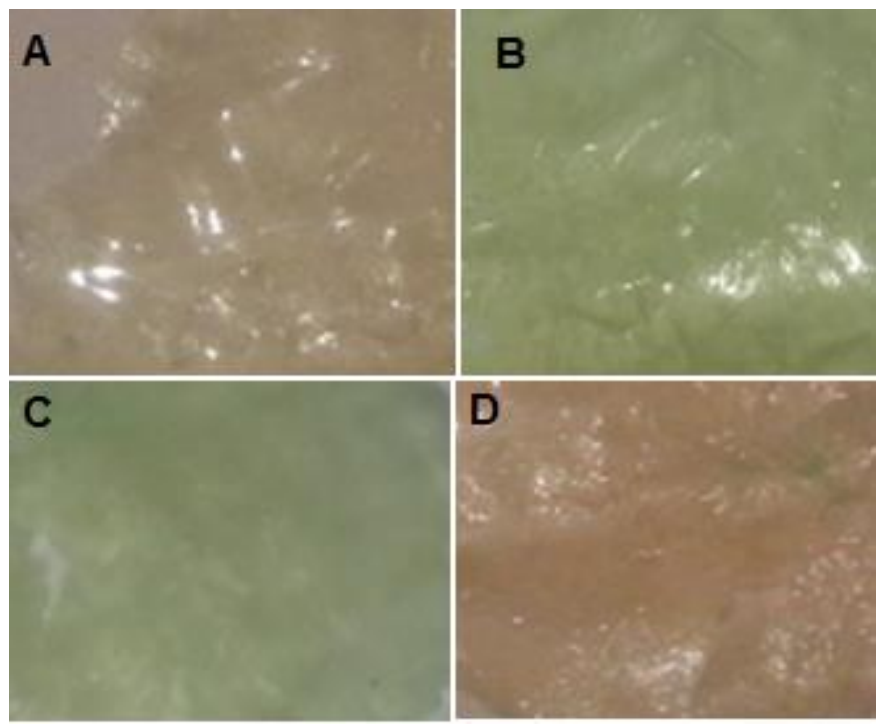

Fig. 3 Realizations of fabricated thin film samples

Moreover, each sample is analysed using laser beam reflection process among many analysis methods $[22,23]$. Some materials may have a good reflection rate than others. So, the sample was placed on polycarbonate substrate and branch it on DVD laser emitter and reader fed by voltage of $3 \mathrm{~V}$. As result the reflected voltage was measured. This technique is simple but it is fruitful to study the optical characteristics. By calculation of voltage ratio, the reflectance data was obtained which is one of the optical properties $[24,25]$ and illustrate in Fig. 4 and sum up the data in Table 3. 
Table 3 Reflection coefficient of samples to laser beam

\begin{tabular}{lll}
\hline Sample ID & Reflected Voltage $(\mathrm{mV})$ & Reflection coefficient $(\%)$ \\
\hline A & 136 & 4.53 \\
B & 74 & 2.47 \\
C & 96 & 3.20 \\
D & 83 & 2.77 \\
\hline
\end{tabular}

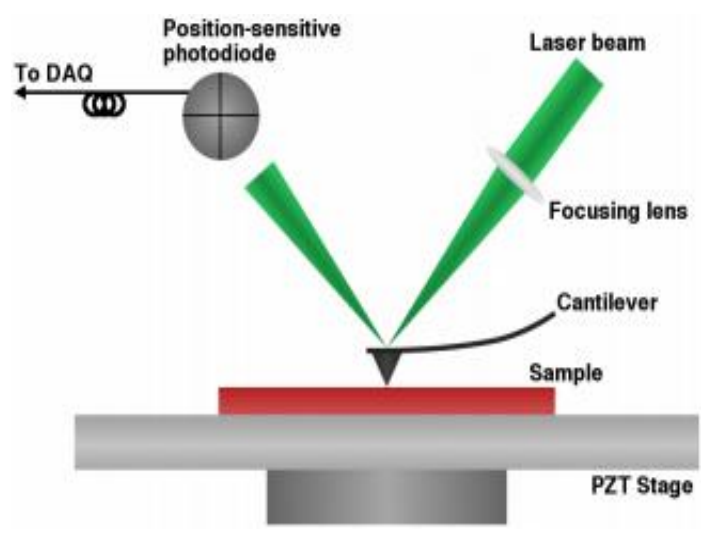

Fig. 4 Emission and reflection of laser beam by sample

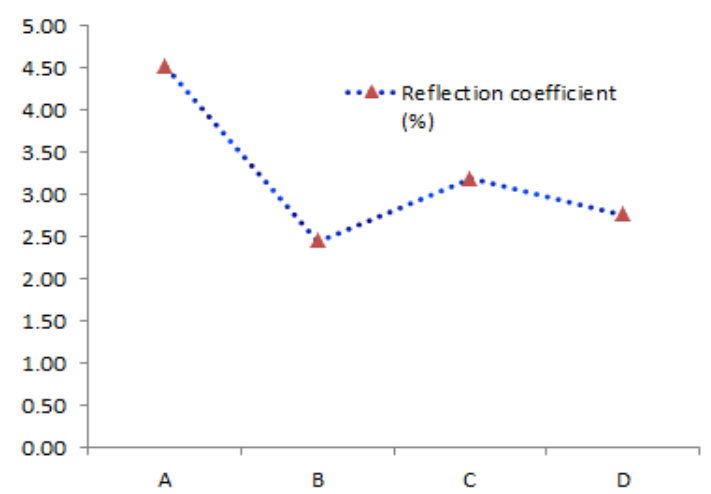

Fig. 5 Reflection coefficient of samples
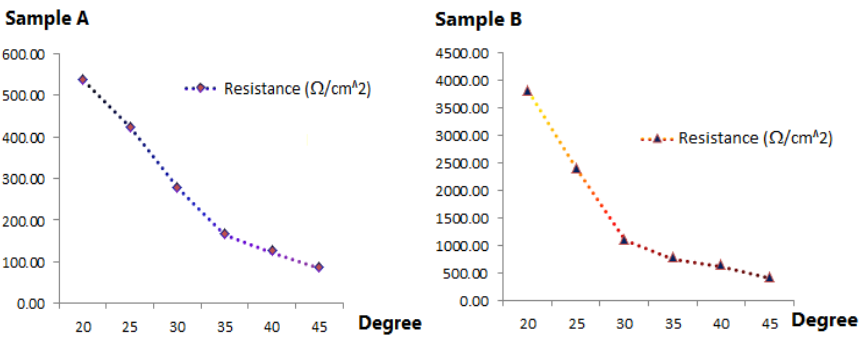

Fig. 6 Variations of resistances with temperature for samples A and B
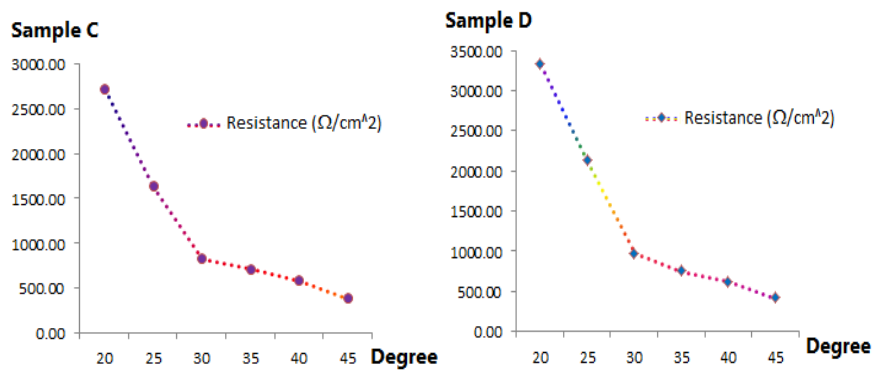

Fig. 7 Evolutions of resistances with temperature for samples C and D

To compare the properties of these samples, their reflection coefficients were studies as represented in Fig. 4. The aluminium has a positive impact on reflection of laser beam, it can be used in many technologies as reflective layers. The zinc is qualified as second material that reflects the beam as we can see in the curves in Fig. 5. However, the lead did not respond to the phenomenon of laser beam reflection with adequate rate. The variations of impedance with temperature is an awesome result that reflects the quality of fabricated thin film. In addition to that, their impedance characters influence on other electrical properties such as resistivity, conductance and electrical potential. To sum up, the evolution of impedances of studied samples in function of temperature are depicted in the Figs. 6 and 7.

https://doi.org/10.30799/jtfr.021.19030103
The specimens $A$ and $D$ have resemblance but their contents ratios give their different properties as verified from reflection coefficient and impedance evolution. Moreover, the same appearance is observed for B and $\mathrm{C}$ but the chemical composition is different and hence it effects different optical, morphological and electrical characteristics. Therefore, these parameters are very interesting to take in consideration when the processes of semiconductors manufacturing planning. The samples endure high temperature that reaches $65^{\circ} \mathrm{C}$ and so their nanostructure is very lucrative. From the analysis of reflection process the specimens are competitive to their optical properties that can be used widely for intelligent reflective thin layers. Yet, the tests of all samples have performances that can challenge newest thin films qualities [26] such as their flexibility and they have to be analyzed by techniques of the higher frequencies and temperatures.

\section{Conclusion}

This work is an effective contribution to fabricate thin film with high performances. A competitive thin film has been developed that respond to the size of thickness which is at order of many nanometers. The transparency is an aesthetic side that gives the films as a strong challenge in the field of thin film technologies. Yet, the reliability of these nanostructures ensures that alloys constitute an alternative with thermodynamic quality to the flexibility and morphological structure. The endurance to temperature variations confirm that the films keep stable phase and compact surface when external noises such as oxidation and crystallization are absent. The laser beam analysis processed to determine the electrical impedance and optical properties and reveals a promising result.

\section{References}

[1] A. Polman, M. Knight, E.C. Garnett, B. Ehrler, W.C. Sinke, Photovoltaic materials: present efficiencies and future challenges, Science 352 (2016) 307-318.

[2] E.A. Lund, H. Du, W.M. Hlaing, G. Teeter, M.A. Scarpulla, Investigation of combinatorial coevaporated thin film $\mathrm{Cu}_{2} \mathrm{ZnSnS}_{4}$ (II): beneficial cation arrangement in Cu-rich growth, J. Appl. Phys. 115 (2014) 14227-14237.

[3] J.J.S. Scragg, J.K. Larsen, M. Kumar, C. Persson, J. Sendler, et al., Cu-Zn disorder and band gap fluctuations in $\mathrm{Cu}_{2} \mathrm{ZnSn}(\mathrm{S}, \mathrm{Se})_{4}$ : theoretical and experimental investigations, Phys. Status Solid. 253 (2015) 247-254.

[4] A. Tang, Z. Li, F. Wang, M. Dou, J. Liu, J. Ji, Y. Song, Electrodeposition mechanism of quaternary compounds $\mathrm{Cu}_{2} \mathrm{ZnSnS}_{4}$ : effect of the additives, Appl. Surf. Sci. 427 (2018) 267-275.

[5] N.A. Shvab, V.D. Litovchenko, L.M. Rudkovskaya, Mechanism of reduction of thiosulfate ions on the cathode, Russ. J. Appl. Chem. 80 (2007) 1852-1855.

[6] Y. Leng, Materials characterization: introduction to microscopic and spectroscopic methods, Wiley, Weinheim, Germany, 2013.

[7] M. Guo, X. Zhu, H. Li, Comparative study of $\mathrm{Cu}_{2} \mathrm{ZnSnS}_{4}$ thin film solar cells fabricated by direct current and pulse reverse co-electrodeposition, J. Alloys Compd. 657 (2016) 336-340.

[8] B. Unveroglu, G. Zangari, Towards phase pure Kesterite CZTS films via Cu-ZnSn electrodeposition followed by sulfurization, Electrochim. Acta 219 (2016) 664 672.

[9] L. Atourki, E.H. Ihalane, H. Kirou, K. Bouabid, A. Elfanaoui, et al. Characterization of nanostructured $\mathrm{ZnO}$ grown by linear sweep voltammetry, Sol. Energy Mater. Sol. Cells 148 (2016) 20-24.

[10] C. Gougaud, D. Rai, S. Delbos, E. Chassaing, D. Lincot, Electrochemical studies of one-step electrodeposition of $\mathrm{Cu}-\mathrm{Sn}-\mathrm{Zn}$ layers from aqueous electrolytes for photovoltaic applications, J. Electrochem. Soc. 160 (2013) D485-D494.

[11] J. Tao, J. Liu, L. Chen, H. Cao, X. Meng, et al., 7.1\% efficient co-electroplated $\mathrm{Cu} 2 \mathrm{ZnSnS} 4$ thin film solar cells with sputtered CdS buffer layers, Green Chem. 18 (2016) 550-557.

[12] J. Tao, L. Chen, H. Cao, C. Zhang, J. Liu, et al., Co-electrodeposited $\mathrm{Cu}_{2} \mathrm{ZnSnS}_{4}$ thin film solar cells with over $7 \%$ efficiency fabricated via fine-tuning of the $\mathrm{Zn}$ content in absorber layers, J. Mater. Chem. A 4 (2016) 3798-3805.

[13] D. Liedekerke, Marcel, Zinc oxide (zinc white): Pigments, inorganic, Ullmann's Encyclopdia of Industrial Chemistry, Wiley-VCH, Weinheim, 2006.

[14] J. Li, D.B. Mitzi, V.B. Shenoy, Structure and electronic properties of grain boundaries in earth-abundant photovoltaic absorber Cu2ZnSnSe4, ACS Nano 5 (2011) 8613-8619.

[15] K. Bouabid, M. Nya, A. Ihlal, Effects of $\mathrm{Na}_{2} \mathrm{SO}_{4}$ on the optical and structural properties of $\mathrm{Cu}_{2} \mathrm{ZnSnS}_{4}$ thin films synthesized using co-electrodeposition technique, Opt. Mater. 75 (2018) 471-482.

[16] H. Battez, A. Gonzalez, R. Viesca, J. Fernandez, J. Diazfernandez, et al., CuO, $\mathrm{ZrO}_{2}$ and $\mathrm{ZnO}$ nanoparticles as antiwear additive in oil lubricants, Wear. 265 (2008) 422-428.

[17] A.A. Dubale, A.G. Tamirat, H.M. Chen, T.A. Berhe, C.J. Pan, et al., A highly stable $\mathrm{CuS}$ and $\mathrm{CuSePt}$ modified $\mathrm{Cu}_{2} \mathrm{O} / \mathrm{CuO}$ heterostructure as an efficient photocathode for the hydrogen evolution reaction, J. Mater. Chem. A 4 (2016) 2205-2216.

[18] Ü. Özgür, Alivov, Y.I. Liu, C. Teke, A. Reshchikov, et al., A comprehensive review of ZnO materials and devices, J. Appl. Phys. 98(4) (2005) 041301:1-103.

[19] A. Fairbrother, X. Fontane, V. Izquierdo-Roca, M. Espíndola-Rodríguez, S. Lopez-Marino, et al., On the formation mechanisms of $\mathrm{Zn}^{-r i c h ~} \mathrm{Cu}_{2} \mathrm{ZnSnS}_{4}$ films 
prepared by sulfurization of metallic stacks, Sol. Energy Mater. Sol. Cells 112 (2013) 97-105.

[20] A. Fairbrother, X. Fontane, V. Izquierdo-Roca, M. Espíndola-Rodríguez, S. Lopez-Marino, et al., On the formation mechanisms of $\mathrm{Zn}$-rich $\mathrm{Cu}_{2} \mathrm{ZnSnS}_{4}$ films prepared by sulfurization of metallic stacks, Sol. Energy Mater. Sol. Cells 112 (2013) 97-105.

[21] B.G. Kutchko, A.G. Kim, Fly ash characterization by SEM-EDS, Fuel 85 (2006) 2537-2544.

[22] M.C. Meyer, P. Austin, P. Tropper, Quantitative evaluation of mineral grains using automated SEM-EDS analysis and its application potential in optically stimulated luminescence dating, Radiat. Meas. 58 (2013) 1-11.
[23] J. Chininis, P.J. Whiteside, H.K. Hunt, Metal-clad waveguide characterization for contact-based light transmission into tissue, Proc. SPIE, Photon. Therap. Diagnos. 12 (2016) 968915

[24] S. Zhu, A.W. Yu, D. Hawley, R. Roy, Frustrated total internal reflection: A demonstration and review, Am. J. Phys. 54 (1986) 601-607.

[25] M. Hamdi, A. Oueslati, A. Lafond, C. Guillot-Deudon, F. Hlel, Structural, morphological and electrical properties of $\mathrm{Cu}_{2} \mathrm{ZnSn}_{1-\mathrm{x}} \mathrm{Si}_{\mathrm{x}} \mathrm{S}_{4}(\mathrm{x}=0.8, \mathrm{x}=1)$ for solar-cells applications, J. Alloys Compd. 674 (2016) 73-81.

[26] L. Essaleh, G. Marín, S.M. Washim, A. Alimoussa, Dynamic conduction in p-type $\mathrm{CuIn}_{3} \mathrm{Se}_{5}$, Superlattice. Microst. 92 (2016) 353-358. 